\title{
A comparative study on the recruitment of shoulder stabilizing muscles and types of exercises
}

\author{
João Carlos Comel',*, Rosane Maria Nery², Eduardo Lima Garcia ${ }^{3}$, Claudete da Silva Bueno', Edinara de Oliveira Silveira ${ }^{1}$, \\ Mariéle Marchezan Zarantonello ${ }^{1}$, Marco Antonio Stefani ${ }^{3}$ \\ ${ }^{1}$ Cenecista College in Santo Angelo, Santo Angelo, Brazil \\ ${ }^{2}$ Hospital de Clínicas de Porto Alegre, Porto Alegre, Brazil \\ ${ }^{3}$ Universidade Federal do Rio Grande do Sul, Porto Alegre, Brazil
}

The shoulder is susceptible to disturbances caused by microtraumas due to direct contact of the surrounding skeletal structures or failure of the soft parts of the rotator cuff and other muscles inserted into the glenohumeral joint. The purpose of the study was to compare the electromyographic signal in the stabilizing muscles of the shoulder during the diagonal elevation exercise as recommended by the proprioceptive neuromuscular facilitation (PNF) method and dumbbell exercise. This study is classified as Quase-experiment. Subjects were instructed to perform diagonal standard exercises and the electromyographic signal was detected from pectoralis muscles, middle and upper trapezius of dominant limb in each subject. We observed greater muscular recruit- ment when the PNF method was adopted in comparison with the dumbbell workouts for the trapezius upper and middle fiber muscles and for the major pectoralis $(267,30 \mu \mathrm{v} / 181,02 \mu \mathrm{v} ; 235,76 \mu \mathrm{v} / ; 164,47 \mu \mathrm{v}$; $299,87 \mu \mathrm{v} / 148,69 \mu \mathrm{v} ; P<0.001)$. The PNF method promotes a greater recruitment of the shoulder dynamic stabilizing muscles during diagonal elevation exercises. Being so, such kinesiotherapeutic technique may be effectively used in the prevention, treatment and rehabilitation of shoulder disorders.

Keywords: Shoulder, Proprioceptive neuromuscular facilitation, Lactic acid, Cortisol, Surface electromyography

\section{INTRODUCTION}

An imbalance in movement, overload and impact makes shoulder joints susceptible to disorders caused by micro traumas due to direct contact of surrounding bone structures or failure of soft parts of the rotator cuff and other muscles inserted into the glenohumeral joint (Alizadehkhaiyat et al., 2015; Rega et al., 2012; Soares, 2003).

The shoulder is therefore affected by several disorders whose features may be caused either by intrinsic factors such as diseases of periarticular structures (ligaments, tendons, and synovial pouches) or by extrinsic factors, usually related to age and activities performed by the individuals, common disorders in all populations (Ferreira et al., 2015). Thus, shoulder rehabilitation focuses on two important aspects: flexibility and strength. Several physio- therapeutic methods have been used for the rehabilitation and strengthening of the upper limbs. Among the most popular methods we call attention to elastic resistance and dumbbell workouts during shoulder exercises given their practicality and versatility. Dumbbell workouts during shoulder exercises is strongly recommended as parts of shoulder rehabilitation programs despite the limited evidence available to guide physiotherapists in deciding the type of resistance or the ideal exercise (Ferreira et al., 2017). In line with some previous conducts, proprioceptive neuromuscular facilitation (PNF) represents an additional method to promote shoulder rehabilitation by means of maximum biomechanical stretching and therefore, increased functional movements by muscular and proprioceptive stimulation (Witt et al., 2011).

The PNF is equivalent to diagonal exercises whose main pur-
${ }^{*}$ Corresponding author: João Carlos Comel (iD https://orcid.org/0000-0002-1367-8182 Cenecista College in Santo Angelo, Rua Dr João Augusto Rodrigues, 471-Centro, Santo Angelo, Brazil

Tel: +55-33131922, Fax: +55-33131922, E-mail: joaocomel@gmail.com

Received: December 14, 2017 / Accepted: February 12, 2018
This is an Open Access article distributed under the terms of the Creative Commons Attribution Non-Commercial License (http://creativecommons.org/licenses/by-nc/4.0/) which permits unrestricted non-commercial use, distribution, and reproduction in any medium, provided the original work is properly cited. 
pose is to increase functional movement by muscular facilitation, inhibition, strengthening and relaxation. Such exercises aim to increase range of motion and response to physical effort (Abreu et al., 2015; Tucker and Slone, 2016).

On the other hand, diagonal exercises are commonly used to recruit muscles of the shoulder girdle to which dumbbell workouts and elastic resistance exercises can be adopted and practised. Therefore, studying the diagonal exercises methods becomes crucial as researchers may get theoretical support and decide on a more effective therapeutic choice for muscle strengthening (Lister et al., 2007).

However, defining the most appropriate therapeutical approach can be a challenging task. In this sense, the surface electromyography (SEMG) is a tool used in kinesiotherapeutic protocols both in healthy individuals and in those suffering from disorders. The SEMG technique consists of capturing the electric signal produced in the arrangement of muscles by stimulating motor units of the human body in order to enable the definition and investigation of the muscles that are being used in a certain movement (Andersen et al., 2010; Gaffney et al., 2016).

Thus, we propose a comparative study between the energy expenditure and the muscular recruitment of shoulder stabilizers during the diagonal elevation exercise as recommended by the PNF and conventional dumbbell exercises.

\section{MATERIALS AND METHODS}

\section{Study design}

This study is classified as Quasi-experiment, performed at Clínica Escola de Fisioterapia da Faculdade Cenecista de Santo Ângelo, together with a study group focused on Complementary and Physical Exercises at Hospital de Clínicas located in Porto Alegre (HCPA), both located in Brazil.

\section{Participants}

The study was approved by the HCPA Research Ethics Committee and is registered under the number CAAE 58887916.9. 3001.5571 .

Healthy male and female individuals were included in the study aged between 18 and 35 who performed physical exercises regularly -3 times a week.

Individuals carrying neurodegenerative diseases, psychic illnesses and cognitive delays that prevented them from understanding the proposed therapy were excluded. Individuals under muscular hypertrophy training with partial upper limb amputation were also excluded from the study.

Tests

All participants were received at the physiotherapy school clinic where they signed the written informed consent form and provided personal identification information. Evaluation started by taking notes of blood pressure followed by height and weight checking. The subjective Borg scale (Silva et al., 2011) was used to determine the intensity of exercises practised by means of dumbells and of PNF and the recommended intensity was $75 \%$ of maximum effort (Fig. 1). Each type of exercise was performed in a 24hr interval.

\section{Electric myographic equipment-acquisition and procedure}

Myographic signals were captured by a Miotool USB SEMG, 14 bits resolution, noise $<2 \mathrm{LSB}, 5,000 \mathrm{~V}$ (root mean square [RMS]) safety isolation, charging tension with NiMH batteries, $470 \mathrm{~g}$ approximate weight. The electromyographic signal was captured by surface electrodes (Meditrace electrode 100 - ag/agci - solid gel - hydrogel, sticker and conductor).

The electromyography (EMG) surface for the noninvasive assessment of muscles protocol, by which the electrode is positioned between the distal tendon and the motor point of the evaluated muscle in line with the muscle fibres (Stegeman and Hermens, 2017).

Participants were placed in supine position during the test with both upper limbs placed next to the body. The head was placed in neutral position with semisoft knees on a steady support. The skin was properly sanitized with alcohol soaked cotton to reduce impedance.

The electromyographic signal was captured through surface electrodes placed in the muscle belly of the pectoralis, upper and middle trapezius muscles of dominant limb in each individual ( $\mathrm{Da}$ Paula Rodrigues et al., 2016).

After the positioning of the electrodes, participants were clearly instructed on how to behave and perform the exercises. Once the participants were familiar with the instructions, three free repetitions were observed and registered to facilitate a clearer understanding of the exercise sequence before the final performance with the capture of the gross signal from the belly muscular muscle.

During the PNF technique, the movement was directed by the therapist as a passive demonstration and therefore, promoting a better understanding of the expected activity. Each move was per- 

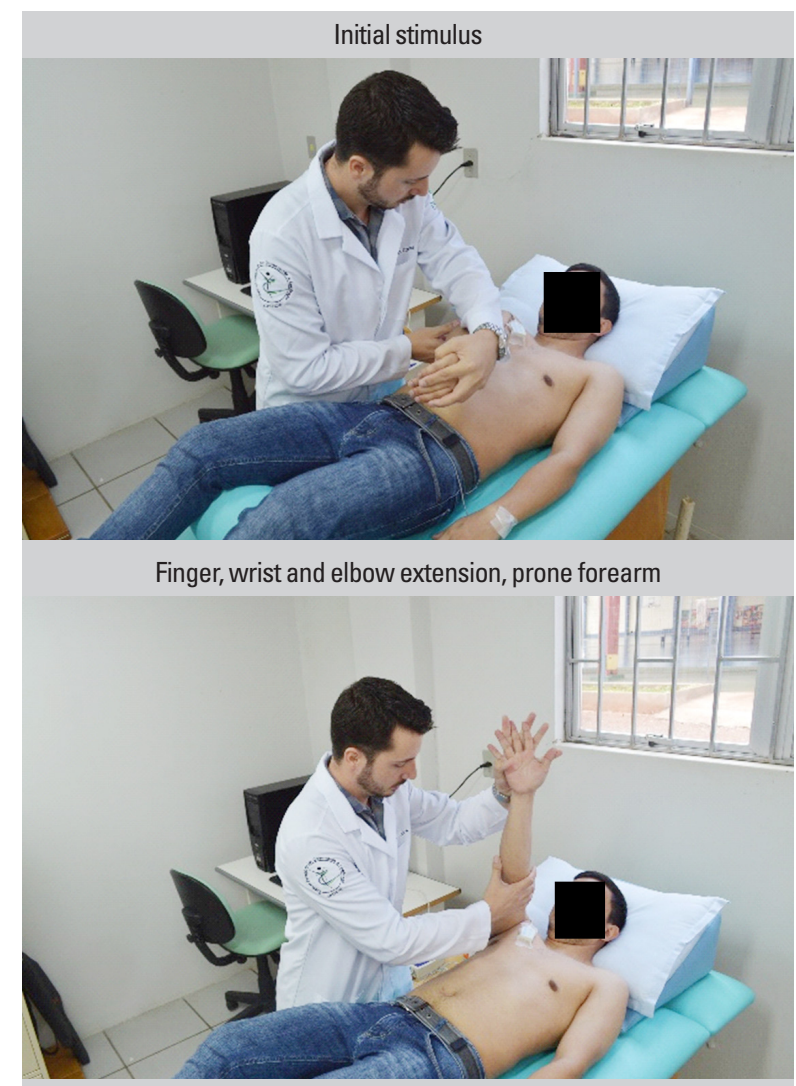

External rotation and abduction

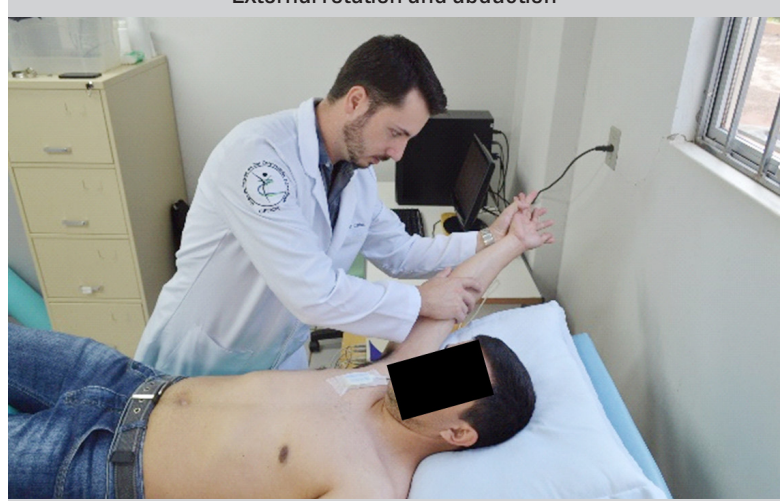

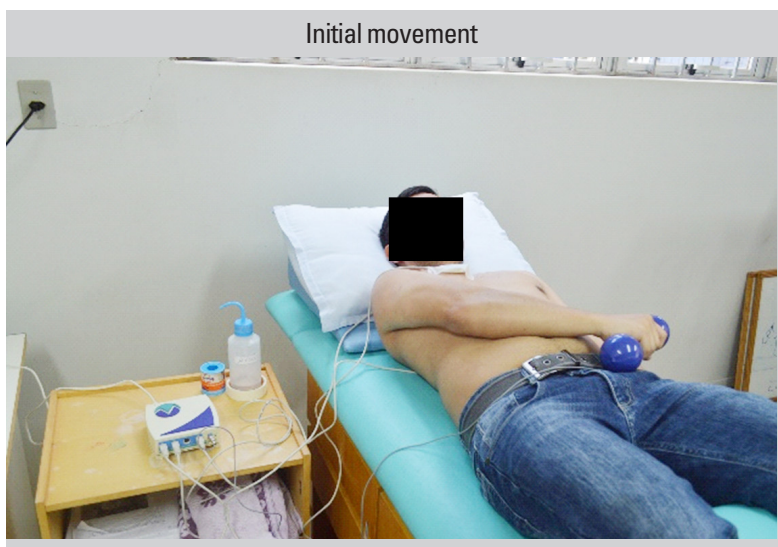

Intermediate movement, external rotation and abduction

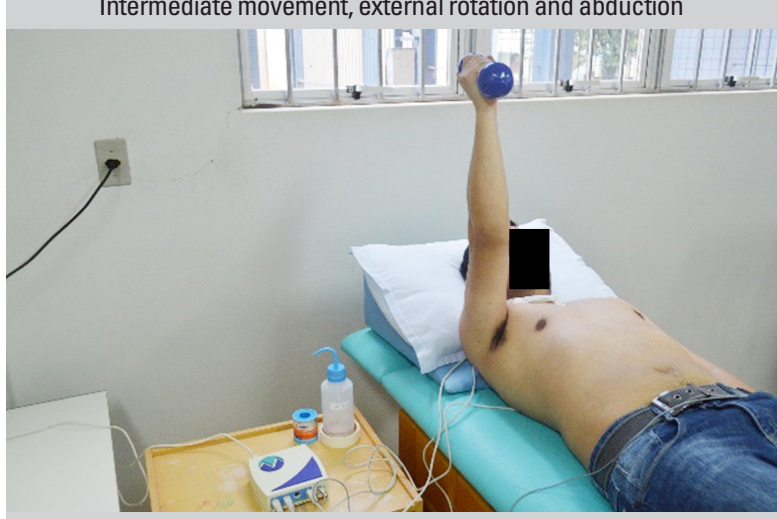

External rotation and abduction

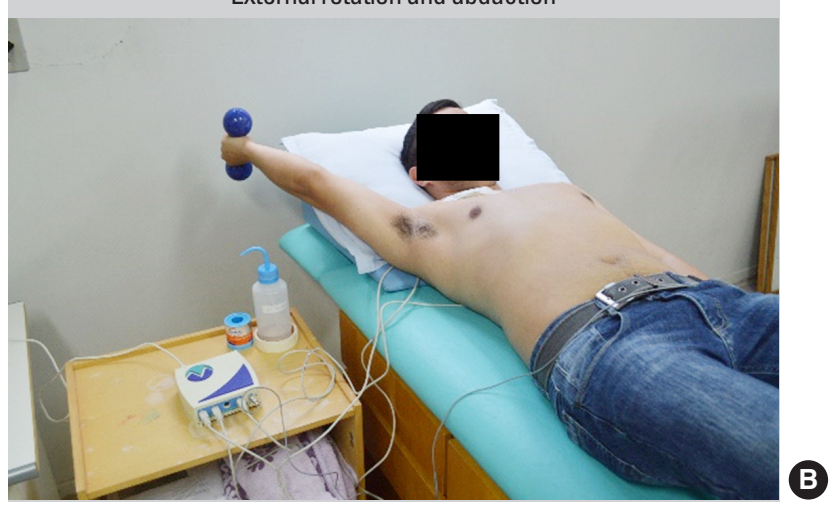

Fig. 1. Proprioceptive neuromuscular facilitation exercise (A) and dumbell exercise (B).

formed after an adequate verbal command was given including instructions on performance and correction. The diagonal 2 (D2) exercise was performed to stimulate the flexor standard muscle. For the PNF technique, the moves were guided by the therapist as passive demonstration for a better understanding. A diagonal 2 (D2) was also performed to stimulate the flexor movement, a performance that depends on finger, wrist and elbow extension, prone forearm, external rotation and abduction. At the same time, the extensor movement was performed including finger flexion, wrist, supination, elbow extension, internal rotation, shoulder flexion and adduction.

For the dumbell technique, participants were positioned in the same way as for the PNF technique and the diagonal move was performed again. The maximum repetition test was useful to determine $75 \%$ (one-repetition maximum) as maximum weight for this type of exercise (Barbosa et al., 2008).

After finishing each type of exercise completely, blood samples were then collected from participants (cortisol and lactate) in or- 
der to check energy expenditure.

\section{Processing and analysis of the collected blood sample}

Blood samplings were collected by a qualified professional immediately after the execution of each category of exercise. The approximate volume of $10 \mathrm{~mL}$ was taken from each participant by means of venous puncture after a 2 -hr fasting period. The total blood volume was separated into lactate serum and fluorinated plasma cortisol.

The serum for the cortisol analysis was obtained in sample standard tubes, thirty minutes after the collection by means of centrifugation for 15 min 3,000 RPM. After being centrifugated, samples were distributed in micro tubes containing $1,000 \mu \mathrm{L}$ and were immediately frozen.

The plasm fluoretate-Na/K-oxalate sample used in the analysis of the lactic acid was also collected and centrifugated $(15 \mathrm{~min} /$ 3,000 RPM). After the centrifugation, the samples were then distributed in micro tubes containing $1,000 \mu \mathrm{L}$ and were immediately frozen. The material was properly stored for posterior clinical analyses. The transportation of the samples followed all legal procedures.

\section{Statistical analyses}

Data processing and analyses were performed by using the IBM SPSS Statistics ver. 20.0 (IBM Co., Armonk, NY, USA) and results were considered significant when $P<0.05$.

The variables were presented through medians and standard deviation. Basal data were normalized by peaks, referring to RMS, peak and median frequency through Student $t$-test considering the two-tailed distribution with equal variance in the two samples. The significance level considered was $5 \%$, two-tailed.

Table 1. Features of participants

\begin{tabular}{lc}
\hline Variable & Value \\
\hline Sex & \\
Female & $15(71)$ \\
Male & $6(29)$ \\
Age $(\mathrm{yr})$ & $22 \pm 2.5$ \\
Weight $(\mathrm{kg})$ & $61 \pm 14.03$ \\
Height $(\mathrm{m})$ & $1.65 \pm 0.07$ \\
Body mass index $\left(\mathrm{kg} / \mathrm{m}^{2}\right)$ & $22.28 \pm 3.99$ \\
Systolic blood pressure $(\mathrm{mmHg})$ & $121 \pm 12.36$ \\
Diastolic blood pressure $(\mathrm{mmHg})$ & $76 \pm 8.10$
\end{tabular}

Values are presented as number (\%) or mean \pm standard deviation.

\section{RESULTS}

Table 1 shows features from the participants of the study.

A higher prevalence of female participants (71\%) was observed being all adults aged $22 \pm 2.5$ years. The average body mass index was $22.28 \pm 3.99 \mathrm{~kg} / \mathrm{m}^{2}$, being considered healthy and normotensive according to blood pressure values.

Table 2 shows the muscular recruitment scores obtained during the performance of the exercises using dumbells and PNF.

All tested muscles presented a higher recruitment when the PNF method was adopted $P<0.05$. The average observed difference was $86,28 \mu \mathrm{v}$ for the pectoralis muscle, for the upper trapezius muscle $71.28 \mu \mathrm{v}$ and for the middle trapezius muscle 151.17 $\mu v$ during the PNF exercise.

Table 3 shows the scores for lactic acid and cortisol immediately after the performance of each exercise.

There was no significant difference in the cortisol levels for the different categories of exercises, $P>0.05$. However, the lactic acid levels were higher for the PNF exercise when compared to the exercise with dumbell as the difference was 1.30.

Table 4 shows the scores associated with concentric and eccentric contraction time in the pectoralis and upper trapezius during exercises with dumbells and PNF.

\section{DISCUSSION}

Male individuals are usually more physically active than female individuals, a relation that seems to contradict our findings as previously shown in Table 1 . Regarding muscle fibers, they vary according to the genetics and daily life activities (Guedes and Grondin, 2002; Salvador et al., 2005). There is a higher percent-

Table 2. Average scores in muscular contractions

\begin{tabular}{lccr}
\hline Muscle & No. & Mean \pm SD $(\mu \mathrm{v})$ & $P$-value \\
\hline Pectoralis & & & 0.002 \\
PNF & 19 & $267.30 \pm 97.22$ & \\
DUMBELL & 19 & $181.02 \pm 79.10$ & \\
Trapezius S. & & & 0.030 \\
PNF & 19 & $235.76 \pm 89.21$ & \\
DUMBELL & 19 & $164.47 \pm 88.52$ & \\
Trapezius M. & & & $<0.001$ \\
PNF & 19 & $299.87 \pm 82.31$ & \\
DUMBELL & 19 & $148.69 \pm 80.97$ &
\end{tabular}

SD, standard deviation; PNF, proprioceptive neuromuscular facilitation; DUMBELL, exercises with weights; Trapezius S., trapezius muscle upper fibers; PNF, proprioceptive neuromuscular facilitation; Trapezius M., trapezius muscle middle fibers. 
Table 3. Average scores for lactic acid and cortisol after the exercises

\begin{tabular}{lccc} 
& No. & Mean $\pm S D(\mu L)$ & $P$-value \\
\hline $\begin{array}{l}\text { Lactic acid } \\
\text { PNF }\end{array}$ & 19 & $3.02 \pm 2.34$ & 0.043 \\
$\quad$ DUMBELL & 19 & $1.71 \pm 1.13$ & \\
Cortisol & & & 0.432 \\
PNF & 19 & $13.284 \pm 7.52$ & \\
DUMBELL & 19 & $12.216 \pm 10.05$ & \\
\hline
\end{tabular}

SD, standard deviation; PNF, proprioceptive neuromuscular facilitation; DUMBELL, exercises with weights.

age of fibers type I in females, which are capable of faster recovery and resistant to weariness, easily stretched, and with higher concentrations of estrogen, whilst in males higher amounts of fiber type II are presented, which are characterised by fast contraction, white, and with higher amounts of testosterone (Carneiro et al., 2002; Minamoto, 2004; Ramires et al., 2014).

Among the muscles that stabilize the shoulder, there are the trapeze and the pectoral. Connecting the superior member to the thorax, the pectoral muscle has the function of perform adduction, flexion, and horizontal flexion of the shoulder (Phadke et al., 2009). On the other hand, the trapeze shoulder, a superficial muscle that connects the superior member to the backbone, is easily recruited in a lot of movements that involve head and shoulders. Therefore, when the muscles of the more profound layer are not strong enough, the trapeze is the most sought, which favors the accumulation of straining (Stapait et al., 2013).

As a consequence of that, the PNF has been used as therapy in order to improve athlete's physical performance, either being sedentary, healthy or dysfunctional. This modality is based on the usage of movements and postures as a therapeutic purpose, which are based in the patterns of facilitation, stretch stimulus, traction-approach, stretch reflexion, manual contacts, verbal command, visual stimulus, resistance, irradiation, reinforcement, and synchronization of movements (Lister et al., 2007; Sullivan and Portney, 1980; Youdas et al., 2012).

Owing to the importance of the training of stabilizer muscle shoulders in the treatment and prevention of injuries, a range of studies with EMG have reported strategies of scapular muscles activation during the exercises. Therefore, this study acknowledges through Table 2, the hypothesis that there is difference in the recruitment of muscle fibers to the execution of different techniques of diagonal elevation exercises. We performed the diagonal D2, in which there was resistance until the individual's effort reached $75 \%$ of maximum strength. The entire exercise was performed with constant stimulus made by spoken words and appropriate
Table 4. Average time of concentric and eccentric contractions observed during diagonal elevation

\begin{tabular}{lccc}
\hline & No. & Mean \pm SD & $P$-value \\
\hline Average time (sec) & & & $<0.001$ \\
PNF & 19 & $6.52 \pm 1.30$ & \\
DUMBELL & 19 & $4.98 \pm 0.26$ & \\
\hline
\end{tabular}

SD, standard deviation; PNF, proprioceptive neuromuscular facilitation; DUMBELL, exercises with weights.

voice intonation in order to orientate the activity, similar to the manual format in which the strength and movement were guided with touch and pressure (Lister et al., 2007).

According to what was described in the Youdas et al. (2012) study, which compared the muscle activation of eight muscles of the shoulder and body during an activity with halter during the two diagonals in the scapular surface, the D1 flexion (shoulder's flexion, adduction, and external rotation) and D2 flexion (shoulder's flexion, abduction, and external rotation), the authors found that the trapeze muscle of medium fiber had a greater activation in $\mathrm{D} 2$ than in D1. This data was also found in our study, in which was realized a greater muscle recruitment compared to the other fibers.

Among the metabolic and endocrine adaptations observed during the performance of a resisted physical effort, the cortisol hormone is highlighted (Rosa et al., 2010). The hormonal response to the exercise depends on various factors, including intensity, duration, manner and level of training (Bueno and Gouvêa, 2012). However, the levels of cortisol presented were not statistically significant, as shown in the Table 3 , what we can consider is the age factor and the fact that a specific time of the day was not standardized for the collect of data.

The Table 4 shows data from the combined contraction of the muscles that perform concentric and eccentric force and the PNF exercise demonstrated a higher consistency of muscular contraction compared to the exercise with dumbells.

Regarding the musculature, the agonists and antagonists muscles act in opposite directions, reacting to voluntary or involuntary stimulus in an eccentric and concentric way of contraction, acting directly as a dynamic joint stabilization (Paz et al., 2013).

Da Fonseca et al. (2007) describes that when the agonist muscle reaches final amplitude of contraction, it begins to cause proprioceptive stimulation of the antagonist muscle, resulting in resistance to the final phase of the agonist movement, then occurring the so called cocontraction. Such event acts in the stability with anticipatory adjustments and reactives evidenced by myoelectric activity of the muscles that intersect a specific joint. Thenceforth, 
considering the concentration of lactic acid, it presents a lower amount in the eccentric work if compared to the concentric, for it presents lower metabolic demand (Oliveira et al., 2006).

In the Table 2, there is a greater muscle recruitment in the modality of PNF exercise, which also promotes a greater time of simultaneous contraction between the agonists and antagonists. According to this, Youdas et al. (2012) points out that the PNF technique is based on applying diagonal movements, the most functional as possible, in which is possible to achieve a cocontraction of agonists and antagonists muscles through the rhythmic stabilization. In our study, a simultaneous contraction of the major pectoral and superior trapeze muscles occurred, demonstrating that PNF not only reinforces the proprioception, but also offers a constant stimulus that improves the muscle performance of the scapular waist.

Therefore, the cocontraction contributes significantly to the dynamic stability of the shoulder improving the joint stabilization through the increase of muscle strength, flexibility and gain in the movement and amplitude, since this joint presents a lot of degrees of freedom and is likely to injuries and instabilities (Garzedin et al., 2008).

\section{CONFLICT OF INTEREST}

No potential conflict of interest relevant to this article was reported.

\section{REFERENCES}

Abreu R, Lopes AA, Sousa AS, Pereira S, Castro MP. Force irradiation effects during upper limb diagonal exercises on contralateral muscle activation. J Electromyogr Kinesiol 2015;25:292-297.

Alizadehkhaiyat O, Hawkes DH, Kemp GJ, Frostick SP. Electromyographic analysis of the shoulder girdle musculature during external rotation exercises. Orthop J Sports Med 2015;3:2325967115613988.

Andersen LL, Andersen CH, Mortensen OS, Poulsen OM, Bjørnlund IB, Zebis MK. Muscle activation and perceived loading during rehabilitation exercises: comparison of dumbbells and elastic resistance. Phys Ther 2010;90:538-549.

Barbosa RI, Marcolino AM, Fonseca MC, Mazzer N, Zatiti SC. Retrospective functional assessment of patients with humerus proximal fractures internally fixed with a fixed-angle plate for proximal humerus area. Acta Ortop Bras 2008;16:89-92.

Bueno JR, Gouvêa CM. Cortisol e exercício: efeitos, secreção e metabolismo. Rev Bras Pres Fisiol Exer 2012;5:435-445.
Carneiro AL, Lopes T, Moreira AL. Mecanismos de adaptação ao exercício Físico. Porto (Portugal): Faculdade de Medicina da Universidade do Porto. 2002.

Da Fonseca ST, Ocariano JM, da Silva PL, Bricio RS, Costa CA, Wanner LL. Caracterização da performance muscular em atletas profissionais de futebol. Rev Bras Med Esp 2007;13:143-147.

Da Paula Rodrigues AL, Feitosa DR, Banja TL, Torres IN. Analysis electromyographic muscle chest and largest lats pulled in years ahead, pull behind and pulled supinated. Rev Bras Pres Fisiol Exer 2016;10: 254-260.

Ferreira AH, Godoy PB, Oliveira NR, Diniz RA, Diniz RE, Padovani RC, Silva RC. Investigation of depression, anxiety and quality of life in patients with knee osteoarthritis: a comparative study. Rev Bras Reumat 2015;55:434-438.

Ferreira DV, Gentil P, Ferreira-Junior JB, Soares SRS, Brown LE, Bottaro M. Dissociated time course between peak torque and total work recovery following bench press training in resistance trained men. Physiol Behav 2017;179:143-147.

Gaffney B, Maluf KS, Davidson BS. Evaluationof novel EMG biofeedback for postural correction during computer use. Appl Psychophysiol Biofeedback 2016;41:181-189.

Garzedin DD, Matos MA, Daltro CH, Barros RM, Guimarães A. Pain severity in patients with painful shoulder syndrome. Act Ortop Bras 2008;16:165-167.

Guedes DP, Grondin LM. Percepção de hábitos saudáveis por adolescentes: associação com indicadores alimentares, prática de atividade física e controle de peso corporal. Rev Bras Ciên Esp 2002;24:23-45.

Lister JL, Del Rossi G, Ma F, Stoutenberg M, Adams JB, Tobkin S, Signorile JF. Scapular stabilizer activity during Bodyblade, cuff weights, and Thera-Band use. J Sport Rehabil 2007;16:50-67.

Minamoto VB. Classificação e adaptações das fibras musculares. Fisiot Pesq 2004;12:50-55.

Oliveira, Baldissera V, Simões HG, Aguiar AP, Azevedo PH, Poian PA Perez SE. Identificação do limiar de lactato e limiar glicêmico em exercícios resistidos. Rev Bras Med Esp 2006;12:333-338.

Paz GA, Maia MF, Santiago FLS, Lima VP, Miranda HL. Efeito da facilitação neuromuscular proprioceptiva e pré-ativação dinâmica dos antagonistas sobre a força isométrica máxima e sinal eletromiográfico. Rev Bras Ciên Mov 2013;21:71-81.

Phadke V, Camargo P, Ludewig P. Scapular and rotator cuff muscle activity during arm elevation: A review of normal function and alterations with shoulder impingement. Rev Bras Fisioter 2009;13:1-9.

Ramires V, Becker LA, Sadovsky AD, Zago AM, Bielemann RM, Guerra $\mathrm{PH}$. Evolution of the epidemiologic physical activity and sedentary behavior research in Brazil: update of a systematic review. Rev Bras 
Ativ Fís Saúde 2014;19:529-547.

Rega RM, Neves MC, Piffer CC. Aspecto anatômico e clínico da articulação do ombro para estudantes de fisioterapia e educação física. Corpus Sci 2012;8:16-20.

Rosa G, Mello DB, Biehl C, Dantas EH. Níveis de cortisol em adultos com sobrepeso submetidos a treinamento concorrente. Braz J Spor Exer Res 2010;1:11-15.

Salvador EP, Cyrino ES, Gurjão AL, Dias RM, Nakamura FY, Oliveira AR. Comparação entre o desempenho motor de homens e mulheres em séries múltiplas de exercícios com pesos. Rev Bras Med Esp 2005;11: 257-261.

Silva AC, Dias MR, Bara Filho M, Lima JR, Damasceno VO, Miranda H, Novaes JS, Robertson RJ. OMNI and Borg scales for the prescription of cycle ergometer exercise. Rev Bras Cineantropom Desempenho Hum 2011;13:117-123.

Soares ST. Trabalho preventivo para lesões de ombro e cintura escapular em atletas amadores de judô. Rev Bras Ciên Mov 2003;11:29-34.

Stapait EL, Dalsoglio M, Ehlers AM, Santos GM. Role of scapular stabilizers strengthening in the painful shoulder: a systematic review. Fisioter
Mov 2013;26:667-675.

Stegeman DF, Hermens HJ. Standards for surface electromyography: the European project Surface EMG for non-invasive assessment of muscles (SENIAM). Enschede (the Netherlands): Roessingh Research and Development 2017. p. 108-112.

Sullivan PE, Portney LG. Electromyographic activity of shoulder muscles during unilateral upper extremity proprioceptive neuromuscular facilitation patterns. Phys Ther 1980;60:283-288.

Tucker WS, Slone SW. The acute effects of hold-relax proprioceptive neuromuscular facilitation with vibration therapy on glenohumeral internal-rotation deficit. J Sport Rehabil 2016;25:248-254.

Witt D, Talbott N, Kotowski S. Electromyographic activity of scapular muscles during diagonal patterns using elastic resistance and free weights. Int J Sports Phys Ther 2011;6:322-332.

Youdas JW, Arend DB, Exstrom JM, Helmus TJ, Rozeboom JD, Hollman $\mathrm{JH}$. Comparison of muscle activation levels during arm abduction in the plane of the scapula vs. proprioceptive neuromuscular facilitation upper extremity patterns. J Strength Cond Res 2012;26:1058-1065. 